\title{
Design, Simulation and Production of Hydraulic Briquette Press for Metal Chips
}

\author{
Bisrat M. Kebede ${ }^{1}$, Hirpa G. Lemu ${ }^{2 *}$ \\ 1 School of Mechanical Engineering, Jimma University, Ethiopia \\ 2 Faculty of Science and Technology, University of Stavanger, N-4036 Stavanger, Norway \\ * Corresponding author's e-mail: hirpa.g.lemu@uis.no
}

\begin{abstract}
Removal of metal chips is involved in several industrial production processes that machine from casted parts by various operations such as turning, milling and drilling. In addition to the fact that the chips represent a treat to the environment, their storage requires a large surface area. The objective of the project reported in this article is to improve the current layout of a machining workshop aimed at minimizing the material handling cost, increasing operator safety, improving flexibility for operation, minimizing the overall cost and utilizing the available area. The research project focused on the compaction of metal chips briquette for simplicity of storage as well as handling and transportation of metal chips for Hibret Manufacturing and Machine Building Industry (HMMBI) factory. The machining process on CNC lathe and milling machines in this company produces $1500-2000 \mathrm{~kg}$ chips $/ \mathrm{month}$. An effective design of hydraulic briquette press is carried out by using a solid modelling tool and simulating the hydraulic circuit. The result of the designed machine was observed to address the stated problems of the company.
\end{abstract}

Keywords: metal chips, briquettes, compacting machine, chip conveyor, computer aided design, finite element analysis, chip recycling.

\section{INTRODUCTION}

Many industrial production processes include mechanical machining of cast parts by means of turning, milling and drilling, producing large quantities of chips on the daily basis. In most cases, these chips are collected in the plant without any further use, occupying valuable floor area of the plant. Afterwards, the industry either sells the metal scrap/chips to a third-party consumer for a low price or opts to dump the chips into the environment [1]. Thus, enabling sustainable machining process by minimizing machining wastes (chips) has a significant impact on the global concern for environmental problems. In addition to minimizing waste, which includes also the reuse and recycling of waste, sustainable machining process implies a lower energy consumption, efficient use of natural resources, utilization of recyclable materials, etc. [2]. From the environmental pollution standpoint, sustainability of the manufacturing process can be addressed from three perspectives or three dimensions: technology, energy and material [3], which influence each other and play a key role in achieving sustainable manufacturing. Metal chips can be recycled indefinitely though several factors including the product mix, which consists of several materials, hindering the process [4]. However, if these wastes of metal chips are recycled, they could not only reduce the pollution to the environment, but also enhance the economic profit for the industry. Therefore, the benefits are both local (for the industry) and global (for the society at large).

In particular, recycling of metal chips is essential nowadays due to the limitations in obtaining raw materials and the energy cost related issues. The efficient recycling of these waste metal chips is very important for both national economy and environmental reasons [4]. The melting and casting method, which is one of the widely used recycling methods is known to consume energy to 
re-melt and form the metal chips. This form of recycling is also not an effective method in terms of high melting losses, high oxidation and gas emission that affect the environment negatively. For this reason, studies for more effective recycling of metal chips and treatment of the lubricant have continued increasingly [5].

Due to these reasons, recent studies have also focused on this recycling issue and a number of methods and technologies are proposed. For instance, Gronostajski and Matruszak [6] developed the method based on plastic deformation of chips from semi-finished products of aluminum and its alloys that are difficult to recycle using the conventional methods. Instead of melting the chips, as it is done in the conventional method, this method uses a powder metallurgy technique and extrusion process to convert the chips into products. Other methods proposed in the literature include pulverization of the chips that are further processed by sintering and hotworking [7], continuous friction stir extrusion [8] and pressing and extrusion [9].

The issue of briquetting of metal wastes is studied from different points of view in the industry. Borowski and Kuczmaszewski [10] reported a study conducted to identify the factors that affect the briquette strength of metal wastes in bearing industries by investigating the physical-chemical properties of the binder materials. The study has further examined the economic and ecological impacts of the metal wastes in industrial applications and the possibilities of waste management solutions by recycling in steel-making industries. In a recent publication, Cooper et al. [11] also studied the possibilities of using extrusion as a step of pre-melting in order to improve the recovery of recycled aluminum and zinc chips. In this study, an attempt is done to predict the oxide content and the recovery rate is compared with other methods.

In this article, a design of briquetting or compaction of metal chips for simplicity of storage and handling for further recycling process was described. The article, following this introduction section, presents the materials and methods, used in the reported design and production of the briquetting machine, are presented. After presenting the key elements of the used design process, the results are presented and discussed. The discussion of the results focused on the design results and the finite element analysis conducted on loaded mechanical components. The last section presents the conclusions.

\section{MATERIALS AND METHODS}

Metal chips that are produced in the metalworking industry can be profitably pressed with hydraulic briquetting systems. Through the process of briquetting, the value of residual metals can be increased considerably. A further advantage is the recovery of expensive cutting fluids that can be pressed out of wet chips and then reused. While melting briquettes, combustion is significantly lower and results in a higher melting yield than with loose chips.

In this study, analytical method of finding the best design result was carried out and computeraided design (CAD) modeling software (Autodesk inventor professional) were employed for both part drawings and developing the 3D models. Furthermore, finite element analysis (FEA) of the hydraulic metal chips briquetting machine was performed for validation of the loads and structure design.

\section{THE DESIGN PROCESS}

The design of hydraulic briquette press for metal chips machine consists of many parts or sub-assemblies having several components or parts that can be classified as standard parts and custom parts. The main feature of this designed machine is that it is purposely designed compact and has a fully automatic function in order to produce briquettes in mold compression chamber. The hydraulic cylinder at the top structure assembly applies $25 \mathrm{kN}$ of force for pressing the metal chips in the mold cavities to increase the density of metal chips or decrease the volume of the chips by approximately $1: 5$ ratio.

\section{Design specifications and assumptions}

While designing, the following specifications and assumptions were considered:

- Metal chips vibration is negligible relative to its weight.

- Setting pressure: $7 \mathrm{MPa}$.

- Time of expansion of piston: $12 \mathrm{sec}$.

- Required stroke: $500 \mathrm{~mm}$.

- Geometrical size of each component was selected based on its cost and compactness.

- Maximum metal chips withdrawal average weight: $1.5-2$ ton in HMMBI.

- Design safety factor: $\mathrm{n}=4$. 
- Maximum feed force permissable for compressing metal chips: $25 \mathrm{kN}$.

- Main motor power: $2.2 \mathrm{~kW}$.

- Input speed: $\mathrm{N}_{1}=1430 \mathrm{rpm}$ and $\mathrm{N}_{2}=\mathrm{N}_{3}=113 \mathrm{rpm}$.

- Machine overall dimension: $L=1900 \mathrm{~mm} ; W=900 \mathrm{~mm}$ and $H=2200 \mathrm{~mm}$.

\section{Hydraulic cylinder selection}

In order to select an optimum type of double acting telescopic cylinder force of $25 \mathrm{kN}$ at the $1^{\text {st }}$ stage in the extension direction at a set pressure of $7 \mathrm{MPa}$, the analyses were conducted considering the following conditions for load rate:

1. At low inertia force: 60 to $80 \%$

2. At high inertia force: 25 to $35 \%$

Since there is high inertia force, the a load rate of $27 \%$ is assumed, and hence the effective area $\left(\mathrm{A}_{\text {eff }}\right)$ is calculated from

$$
A_{\text {eff }}=\frac{\text { Cylinderforce }}{\text { Setpressure } * \text { Loadrate }}
$$

Inserting values gives $A_{\text {eff }}=132.2 \mathrm{~cm}^{2}$, which is further used to select cylinder bore from the recommended standards (partly given in Table 1). Thus, piston type 50 from $1^{\text {st }}$ stage is selected.

\section{Design of gearbox for screw conveyor}

A gearbox is a device for converting the speed and torque on one shaft to another. In this project work, four speed reduction gears were designed, where each of them designed with respect to contact stress, contact fatigue strength and bending strength according to the available design rules and codes. As the pinion gear is considered the most critical in a transmission system, the detailed calculation procedure of this gear was presented in this paper.

The designed pinion is made of a grade 1 steel with a hardness of 262 Brinell tooth surface hardness and through-hardened core. The contact stress, contact fatigue strength and the bending stresses are calculated using equations (2), (3) and (4), respectively.

$$
\begin{gathered}
\sigma_{c}=c_{p} \sqrt{\frac{F_{t} k_{m} k o k_{v} k s}{d_{p} * F * I}} \\
S_{c}=322 H B+200.6 M p a \\
\sigma_{b}=F_{t} k_{v} k s
\end{gathered}
$$

where $F=6.672 \mathrm{~N}$,

$I=0.084$ is a dimensionless constant, which is a function of angle of attack and the gear ratio,

$d_{p}=50.8 \mathrm{~mm}$ is pitch diamater of the pinion,

$F_{t}=165.24 \mathrm{~N}$. In addition, the constants given in Table 2 are used to calculate the stresses and strength parameters.

The calculations show that the designed pinion is exposed to a contact stress of $267.89 \mathrm{MPa}$, and a bending stress of $9.14 \mathrm{MPa}$ while its contact fatigue strength is $782 \mathrm{MPa}$. The values for the rest of the gears can be calculated by following the same procedure with different speed and loading condition.

\section{Design of base and top plate}

The base and top plate are made by casting. Four stages are involved in production of gray cast iron; namely, design, pattern making, mold making and casting.

\section{Design of column}

The stress at any point on the shaft depends on the nature of load acting on it. The load applied on columns is axial. The columns are used to support the top plate which holds the hydraulic

Table 1 Piston effective sectional area [12]

\begin{tabular}{|c|c|c|c|c|}
\hline \multirow{2}{*}{ Type } & \multicolumn{2}{|c|}{ Extended direction } & \multicolumn{2}{c|}{ Retracting direction } \\
\cline { 2 - 5 } & $1^{\text {st }}$ stage & $2^{\text {nd }}$ stage & $1^{\text {st }}$ stage & 9.39 \\
\hline Type 10 & 31.17 & 15.12 & 9.11 & 20.07 \\
\hline Type 20 & 63.62 & 31.42 & 19.44 & 31.82 \\
\hline Type 30 & 95.03 & 47.72 & 31.42 & 39.84 \\
\hline Type 40 & 122.72 & 61.07 & 39.40 & 48.66 \\
\hline Type 50 & 153.94 & 76.00 & 48.25 & $2^{\text {nd }}$ \\
\hline
\end{tabular}


Table 2 Values of correction factors

\begin{tabular}{|l|c|c|}
\hline \multicolumn{1}{|c|}{ Correction factors } & Symbol & Selected value \\
\hline Mounting factor & $\mathrm{k}_{\mathrm{m}}$ & 1.2 \\
\hline Velocity factor & $\mathrm{k}_{\mathrm{v}}$ & 1.4 \\
\hline Stress factor & $\mathrm{k}_{\mathrm{s}}$ & 1.12 \\
\hline Overload factor & $\mathrm{k}_{0}$ & 1.25 \\
\hline Elastic coefficient & $\mathrm{c}_{\mathrm{p}}$ & 191 \\
\hline
\end{tabular}

cylinder (cylinder-2) which is used to press the metal chips vertically. Thus, the columns are designed with respect to buckling according to the guidelines given in Euro code 3. The detailed calculations are omitted.

\section{Design of collar (compactor)}

Collar is attached to piston rod by welding. It has solid circular shape with a diameter of $225 \mathrm{~mm}$ and height of $50 \mathrm{~mm}$. It is used for compressing the metal chips and safety of piston rod.

\section{Design of discharge stage}

Discharge stage is used for discharging out the briquetted metal chips. In addition, it closes the hole of mold cavity when the screw feeds chips and resists the force of the piston. It is a rectangular solid metal made by casting. The discharge plate has the following dimensions: length $\mathrm{L}=250 \mathrm{~mm}$, height, $\mathrm{H}=250 \mathrm{~mm}$ and a width of $\mathrm{w}=100 \mathrm{~mm}$.

Furthermore, the conveyor capacity Q was calculated based on the designed screw diameter $\mathrm{D}(\mathrm{m})$ and pitch $\mathrm{p}(\mathrm{m})$, the speed of the conveyor $N(\mathrm{rpm})$ and the loading efficiency of the screw $\varphi$, as given in Eq. (5).

$$
Q=\frac{60 * \pi}{4} D^{2} * p * N * \varphi * \rho
$$

Where $r$ is the density of the bulk material, $\mathrm{kg} / \mathrm{m}^{3}$.

\section{RESULTS}

\section{Design results}

Upon completing the design, the final result (Figure 1) in terms of the machine weight, hopper volume, compaction volume and compaction rate are as follows:

- Total weight of the machine with and without assembling hydraulic cylinder is $80 \mathrm{~kg}$ and $874.7 \mathrm{~kg}$, respectively. As stated, the goal to keep the machine weight under $954.7 \mathrm{~kg}$ which is successfully achieved.

- Total designed volume of hopper is $0.019685 \mathrm{~m}^{3}$. Such volume can contain roughly $5 \mathrm{~kg}$ of unprocessed metal chips at a time.

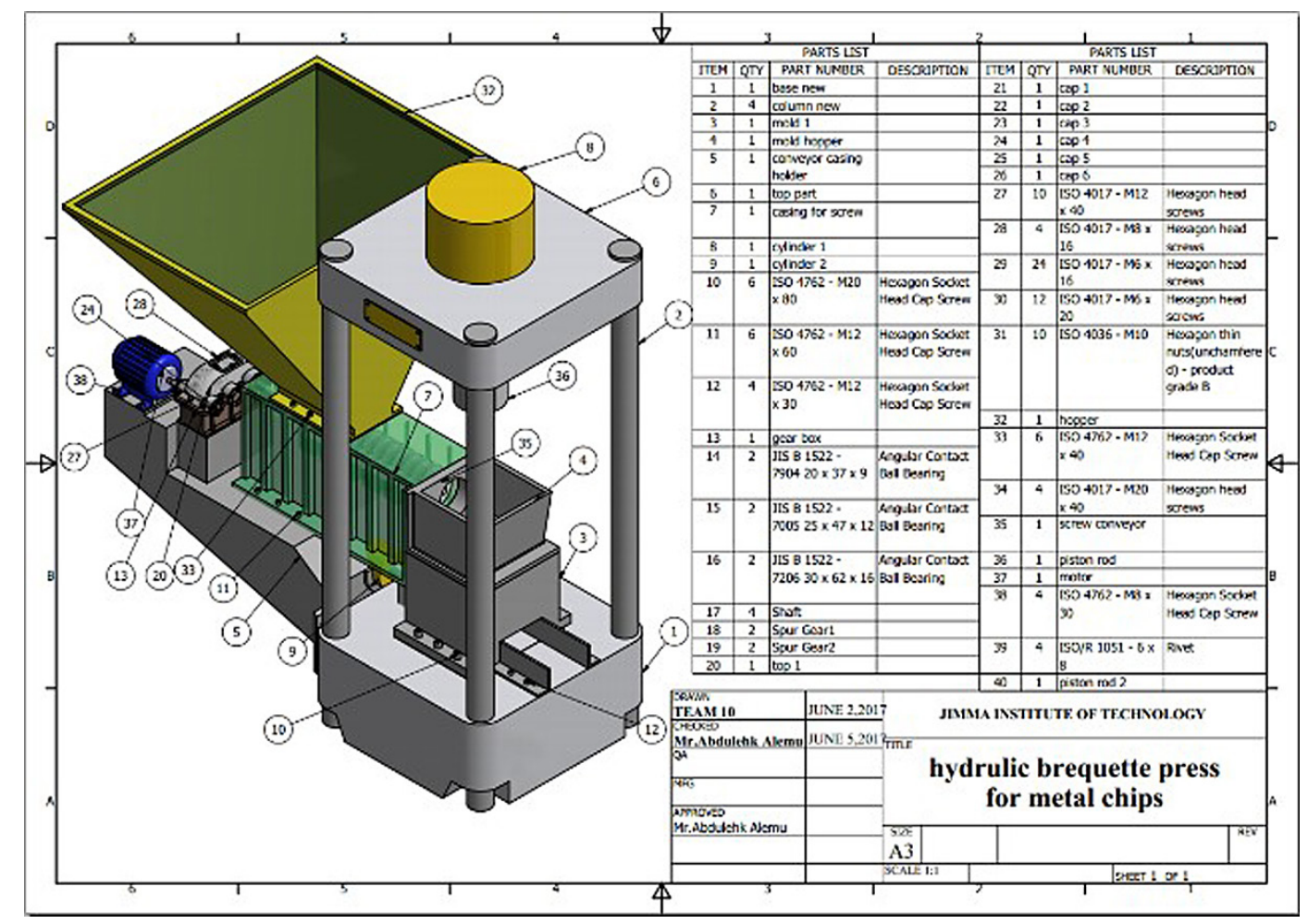

Fig. 1. Final design (3D model) of hydraulic briquette press machine 
a)



b)

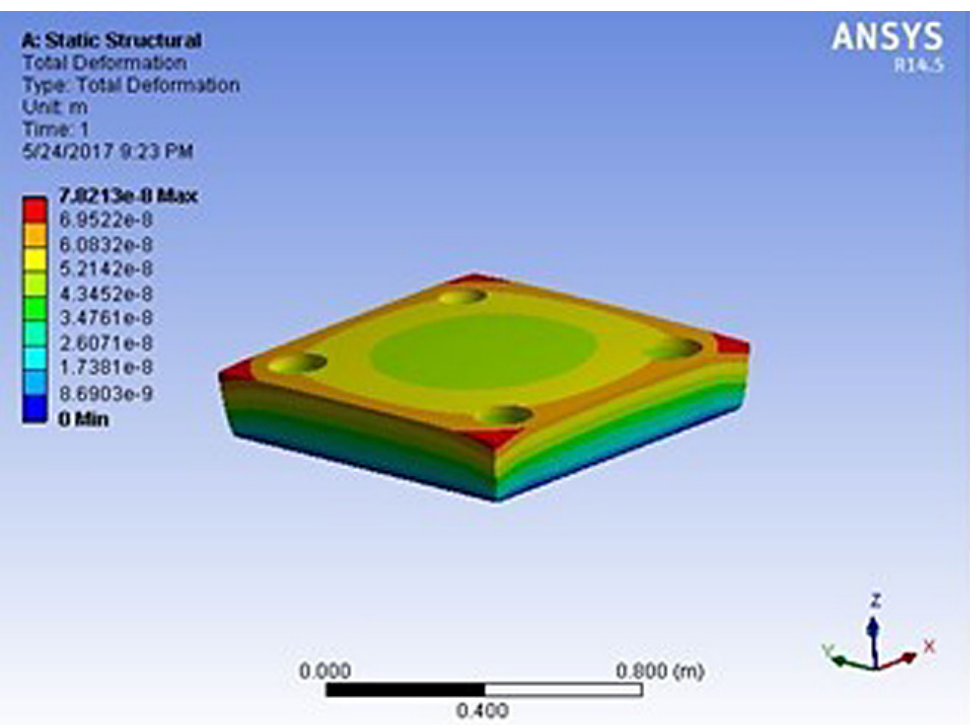

c)

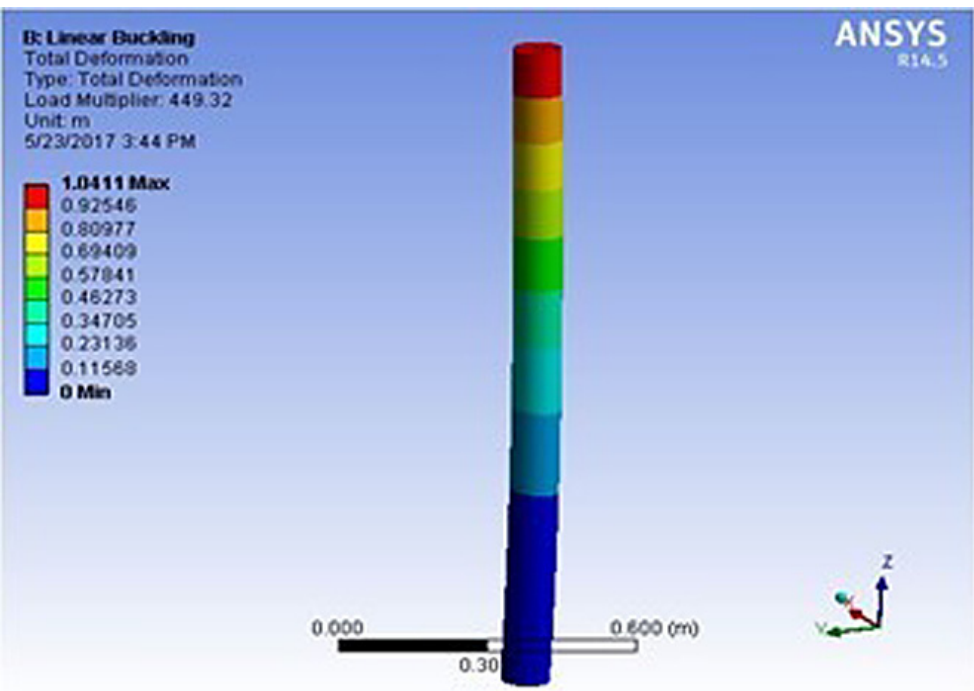

Fig. 2. FEA results (a) total deformation on discharge stage (b) total deformation on the base plate and (c) total deformation on a column (linear buckling) 
However, as hopper cannot be filled completely at once due to the handling issues, less amount of chip is utilized to form briquette which weights $2-3 \mathrm{~kg}$.

- Compression capacity: $0.01142 \mathrm{~m}^{3}$. This gives a volume reduction of $80 \%$, i.e. from a total volume of $0.019685 \mathrm{~m}^{3}$ the chip. However, as the chip is fed in the hopper manually, the compaction percentage may vary for each briquette as per variation in amount of chip fed in the hopper.

- Compaction rate: Briquetting machine takes about 2 to 3 minutes to form a single briquette. That means 20 to 25 briquettes can be formed in $1 \mathrm{hr}$.

\section{FEA of key components of the hydraulic briquette machine}

Calculations were conducted to prove stability and strength of the machine based on the final designed machine configuration. In addition, finite element method (FEM) tool ANSYS is used to observe the stress distribution on the key loaded components of the machine.

The stress contours in Figure 2 show the 3D model and FEM analysis of some parts of the hydraulic briquette machine. In the analysis, the top plate was subjected to body force only, which was further applied to the columns as axial loads (for buckling analysis). The obtained results are depicted in Figure $2(\mathrm{a}-\mathrm{c})$.

\section{DISCUSSIONS}

Metal chips, including iron, steel, and aluminum are actual machined chips that are sized using standardized test sieves and not manufactured from metal powders. Chips (also known as turnings, filings, or shavings), are pieces of metal, wood, or plastic that are the debris or waste resulting from machining, woodworking, or similar subtractive (material-removing) processes. Chips can be small particles (such as the gritty swarf from grinding metal or the sawdust from sawing or sanding wood); long, stringy tendrils such as the springy chips from turning tough metals, or long shavings from whittling or slag-like wastes such as those produced within pipe during pipe fitting work [13].

Chips can be extremely sharp, and this creates a safety problem, as they can cause serious injuries if not handled correctly. Depending on the composition of the material, it can persist in the environment for a long time before degrading. This, combined with the small size of some chips (e.g. those of brass or bronze), allows them to disperse widely by being carried over on soft materials and penetrate skin as deep splinters. In order to solve this problem of metal chips in the workshop, the hydraulic briquette press for metal chips was designed and produced for use at HMMBI (Hibret Manufacturing and Machine Building Industries) in Ethiopia. The machine showed acceptable performance in compressing metal chips of aluminum, bronze, brass and steel chips, though some stability issues were observed, which can be improved in future modifications.

\section{CONCLUSION}

Nowadays, the production of large amount of scrap materials is not only harmful for the industry but also to the environment. Therefore, by developing these techniques we can reduce the wastage of our valuable resources (in this case metals like steel, iron, etc.). By using metal chip reduction technique in the industry, scrap collection in the manufacturing plant area can be eliminated. Using the compressing process of the machine designed and produced in this project, the density of the briquette increased by $1257.57 \mathrm{~kg} / \mathrm{m}^{3}$. The density may be further improved by increasing hydraulic power system. This increases the yield of the material and reduces oxidation of the bulk material. Thereby, the value of briquette can be tripled with respect to the value of loose chips. Therefore, due to volume reduction and definite shape, these briquettes can be easily shipped. This article focused on the design process and the mechanical performance of the briquette machine. The continuing work on the project will focus on the comparative study of the briquetting efficiency with other methods.

\section{Acknowledgments}

The diverse forms of support of Mr. Tarekegn Hailu and Mr. Amenti Bezu are highly acknowledged. Thanks also to Jimma Institute of Technology, School of Mechanical Engineering for providing an opportunity to do the project work. 


\section{REFERENCES}

1. Jayal, A.D., Sustainable manufacturing: Modeling and optimization challenges at the product, process and system levels, CIRP Journal of Manufacturing Science and Technology 2, 2010, 44-52.

2. Pusavec, F., Krajnik P. and Kopac, J., Transitioning to sustainable production - Part I: Application on machining Technologies, Journal of Cleaner Production, 18, 2010, 174-184.

3. Yoan, C., Zhai, Q. and Dornfeld, D., A three dimensional system approach for environmentally sustainable manufacturing, CIRP Annals Manufacturing Technology, 61, 2012, 39-42.

4. Ayres, R. U. Metals recycling: Economic and environmental implications. Resources, Conservation and Recycling, 21(3), 1997, 145-173.

5. Baradie, M.A. Cutting fluids: Part II. Recycling and clean machining, Journal of Materials Processing Technology, 56(1-4), 1996, 798-806.

6. Gronostajski, J. and Matuszak, A., The recycling of metals by plastic deformation: an example of recycling of aluminum and its alloys chips, Journal of Materials Processing Technology, 92-93, 1999, 35-41.

7. Haase, M. and Tekkaya, A.E. Recycling of aluminum chips by hot extrusion with subsequent cold extrusion, Procedia Engineering, 81, 2014, 652-657.

8. Baffari, D., Buffa, G. Campanella, D. and Fratini, L., Design of continuous friction stir extrusion machines for metal chip recycling: issues and difficulties, Procedia Manufacturing, 15, 2018, 280-286.

9. Fogagnolo, J.B. MRuiz-Navas, E. Simón, M.A. and Martinez, M.A., Recycling of aluminium alloy and aluminium matrix composite chips by pressing and hot extrusion, Journal of Materials Processing Technology, 143-144, 2003, 792-795.

10. Borowski, G. and Kuczmaszewski, J., Investigation of briquetting of metal waste from the bearing industry, Waste Management and Research, 23, 2005, 473-478.

11. Cooper, D.R., Song, J. and Gerard, R., Metal recovery during melting of extruded machining chips, Journal of Cleaner Production, 200, 2018, 282-292.

12. Online document: available at http://www.taiyoltd.co.jp/eg/TAIYO_E_WebPDF/red/70T_2.pdf

13. Yang, T., Peters, B. A. and Tu, M., Layout design for flexible manufacturing systems considering single-loop directional flow patterns, European Journal of Operational Research, 164(2), 2005, 440-455. 